\title{
What I Like Is What I Remember: Memory Modulation and Preferential Choice
}

\author{
Ada Aka and Sudeep Bhatia \\ Department of Psychology, University of Pennsylvania \\ Department of Marketing, The Wharton School, University of Pennsylvania
}

\begin{abstract}
Author Note
Funding was received from the National Science Foundation grant SES-1847794, the Alfred P. Sloan Foundation, and Wharton Risk Management Center's Russell Ackoff Doctoral Student Fellowship. We thank Drs. Michael Kahana, Eric Bradlow, Christophe Van den Bulte, and members of the Computational Behavioral Sciences Lab for helpful discussion. Correspondence concerning this manuscript should be addressed to Ada Aka (adaaka@wharton.upenn.edu). Our experiments were pre-registered and our data is accessible at https://osf.io/gjeay/. We also thank participants of 2019 Psychonomic Society Conference, 2019 Society of Judgment and Decision Making Conference, and 2019 American Consumer Research Conference for their helpful discussion during previous conference presentations. No potential conflict of interest was reported by the authors.
\end{abstract}




\begin{abstract}
Memory is a crucial component of everyday decision making, yet little is known about how memory and choice processes interact, and whether or not established memory regularities persist during memory-based decision making. In this paper, we introduce a novel experimental paradigm to study the differences between memory processes at play in standard list recall versus in preferential choice. Using computational memory models, fit to data from two pre-registered experiments, we find that some established memory regularities (primacy, recency, semantic clustering) emerge in preferential choice, whereas others (temporal clustering) are significantly weakened relative to standard list recall. Notably, decision-relevant features, such as item desirability, play a stronger role in guiding retrieval in choice. Our results suggest memory processes differ across preferential choice and standard memory tasks, and that choice modulates memory by differentially activating decision-relevant features such as what we like.
\end{abstract} Keywords: memory, decision making, desirability, memory modulation 


\section{Introduction}

Try to remember the food items currently in your refrigerator. Now try to remember these items with the explicit goal of choosing what to eat for dinner. It is clear that your choice depends fundamentally on memory: An item cannot be selected unless it is successfully recalled. But what is less clear is how the choice task (the goal of selecting something to eat) modulates memory. How do memory processes during preferential decision making compare with memory processes that guide recall when individuals do not have to make a choice?

Most choices that we make on a day-to-day basis are memory-based, with consideration sets and choice items being retrieved from memory at the time of decision. A large body of work has established the importance of memory for many different decisions (e.g., Hertwig, Barron, Weber, \& Erev, 2004; Murty, FeldmanHall, Hunter, Phelps, \& Davachi, 2016). For example, memory's role as an important cue in judgment has been demonstrated with the recognition and fluency heuristics, and formalized within the ACT-R framework (e.g., Gigerenzer \& Goldstein, 1999; Schooler \& Hertwig, 2005; Anderson, 1993). Memory for events also influences their judged likelihood (Dougherty, Gettys, \& Ogden, 1999). Recent work has also studied how prior experiences inform decision making (Shohamy \& Daw, 2015; Bornstein \& Norman, 2017; Carpenter \& Schacter, 2018) and demonstrated that decision making can be biased by contextdependent influences on memory such as primes (Ludvig, Madan, \& Spetch, 2015). Such contextual influences can also alter memory, and subsequently choice, by altering the sequence of thoughts retrieved by decision makers (Johnson, Häubl, \& Keinan, 2007; Weber et al., 2007).

Despite our general understanding that memory has a critical role in many decision making situations, we do not currently know whether and how memory processes at play in 
standard memory paradigms differ from memory processes in preferential choice. Explicitly comparing memory in preferential choice with memory in standard memory tasks is necessary in order to develop theories of preferential choice that build off established memory research, and clearly specify the ways in which choice interacts with memory. Such a comparison is also useful for making novel empirical predictions: If preferential choice relies on mostly the same memory processes as standard tasks, we would expect established memory regularities to persist during choice, and to bias eventual decisions in systematic ways.

Most existing research on memory-based choice has relied on preferential choice tasks, with an emphasis on choice as the primary dependent variable. Although this work has documented some memory effects on choice, it has not been able to directly compare recall in choice with recall in standard memory tasks. We performed such a comparison using a novel experimental task that allows us to elicit recall data as individuals are making choices, and compared this with recall data in standard settings without choice. Our experimental task is based on the list-learning paradigm (Klein, Addis, \& Kahana, 2005; Ward, Tan, \& GrenfellEssam, 2010) commonly used in memory research, and generates free recall data that can be analyzed using many of the established theoretical and statistical tools in memory research, including computational memory models (e.g., Howard \& Kahana, 2002; Polyn, Norman, \& Kahana, 2009). Our task also allows us to test for the emergence of a number of established memory regularities in choice-directed recall. These regularities include serial position effects (primacy and recency), according to which items presented at the start or at the end of the list are more likely to be recalled (Kahana \& Miller, 2013). They also include semantic and temporal clustering effects, according to which recalled items cue the recall of semantically related items 
in the list and items presented in adjacent positions (Kahana, 1996; Sederberg, Miller, Howard, $\&$ Kahana, 2010). Some prior work suggests that serial position and semantic clustering effects may emerge in choice (Sherrick et al., 2016; Hutchinson, Raman, \& Mantrala, 1994; Bhatia, 2019), though we do not currently know if these effects are stronger or weaker in choice relative to memory. Temporal clustering effects, in contrast, have never been studied in choice contexts.

Our experimental task also allows us to examine the role of decision-specific features, like item desirability, in both choice and standard recall. Value has been shown to matter in standard recall (Castel, 2007; Madan, Fujiwara, Gerson, \& Caplan, 2012) and it also likely influences memory-based decision making by cueing the retrieval of desirable items. Building off this prior work, we test whether desirability plays a differential role in preferential choice. Importantly, we focus on subjective values, and unlike existing research, systematically compare the role of value in memory and decision making.

Finally, it is important to mention that the dependent variable of our studies is recall likelihood (i.e., memory). We believe that studying this variable is interesting for decision researchers because changes in memory retrieval influence eventual decision making. In order for an item to be chosen in a memory-based decision making task, it has to first be recalled (Kardes et al., 1993), making memory a crucial step in the choice process. Our paper shows how established insights from the memory literature can be used to understand recall (and eventually choice), while also shedding light on the differences between recall in the context of a decision and standard recall. 


\section{Methods}

Both of our experiments had similar procedures and varied only in terms of their decision domain. Experiment 1 involved food choices (health decision making) and Experiment 2 involved gift choices (social decision making). Our experiments were approved by the University of Pennsylvania Institutional Review Board (IRB) and pre-registered (https://osf.io/gjeay/).

\section{Participants}

Participants $(N=352$; mean age $=33 ; 52 \%$ female in Experiment 1 , and $N=361$; mean age $=34 ; 49 \%$ female in Experiment 2), recruited from Prolific Academic, performed the experiment. All participants were residents of the United States and English was their native language. As Leding (2019) points out, online data collection for memory studies is not only comparable to inperson laboratory studies, but also has a number of advantages such as access to a larger and more representative sample.

\section{Procedure}

Participants were randomly assigned to one of two conditions: standard recall or choicedirected recall. To ensure that differences between our conditions were not due to biased encoding, participants in both conditions were first shown a list composed of twenty-five items, presented one after another, drawn from the experiment's word pool. These were food items in Experiment 1 and gift items in Experiment 2. At the end of the list, participants in the standardrecall condition were asked to list the presented items in the order in which they came to their minds. Participants in the choice-directed recall condition, in contrast, were told to imagine that they had to make a choice involving something to eat (Experiment 1) or giving someone a gift 
(Experiment 2). They were then asked to list the presented items in the order in which they came to their minds, as they deliberated about the decision.

Next, each participant rated the desirability of each item for eating or giving as a gift and indicated how frequently they consumed/gifted each item on a scale from -50 to 50 . We found these two variables to be highly correlated ( $r$ 's>.45, $p$ 's $<.001)$, which could lead to multicollinearity issues in the analysis. Thus, below, we perform our analysis with only the desirability variable ${ }^{1}$.
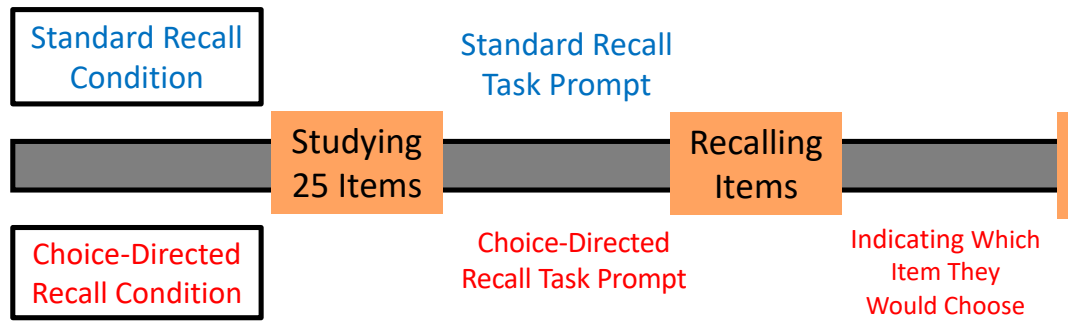

Figure 1. Schematic of the experimental design. The key manipulation of our studies was the recall prompt that participants were shown before retrieving items from their memory. At the end of the list, participants in the standard recall condition were asked to list the words from the list that come their minds, in any order. Participants in the choice-directed recall condition, however, were told to imagine that they had to make a choice involving something to eat (Experiment 1) or giving someone a gift (Experiment 2). They were then asked to list the presented items in the order in which they came to their minds, as they deliberated about the decision.

\footnotetext{
${ }^{1}$ In the Supplemental Materials we reproduce all our results with the frequency of consumption variable and also provide more information about the experimental design.
} 


\section{Results}

\section{Determinants of Absolute Recall}

Participants appeared to have remembered a similar number of unique words in standard recall and choice-directed recall in both of our studies in both Experiment $1(M=10.55, S D=$ 4.03 in standard recall; $M=9.77, S D=4.08$ in choice-directed recall $)$ and Experiment $2(M=$ $8.90, S D=4.83$ in standard recall; $M=8.95, S D=4.58$ in choice-directed recall). To systematically investigate the number of unique words remembered across conditions, we computed 95\% Highest Density Intervals (HDIs) and conducted Bayesian t-tests for the differences between the means. These results provide moderate evidence that the number of unique words remembered by conditions did not significantly differ from one another ${ }^{2}$.

We next investigated the emergence of established memory regularities in our two conditions. We started by examining two different factors that could influence the absolute recall probabilities of items: desirability and serial position. Figures $2 A$ (Experiment 1 ) and $2 B$ (Experiment 2) show the influence of desirability on recall in each of the experiments. We can see that although participants were more likely to recall desirable items than undesirable items in both conditions, this tendency was more pronounced in the choice-directed recall condition (a difference that seems to be driven by the diminished retrieval of less desirable items in choicedirected recall). Similarly Figure 2C (Experiment 1$)$ and $2 D$ (Experiment 2$)$ show the aggregate probability of recall for items based on their serial position. It indicates that primacy effects emerged in both conditions, but there were no major differences between these effects across the choice-directed and standard recall conditions. While we see hints of a recency effect, it is not

\footnotetext{
${ }^{2}$ Please see Supplemental Materials for details of the HDIs and Bayesian t-tests.
} 
statistically reliable in either condition, which is common in scenarios where primacy is very strong.
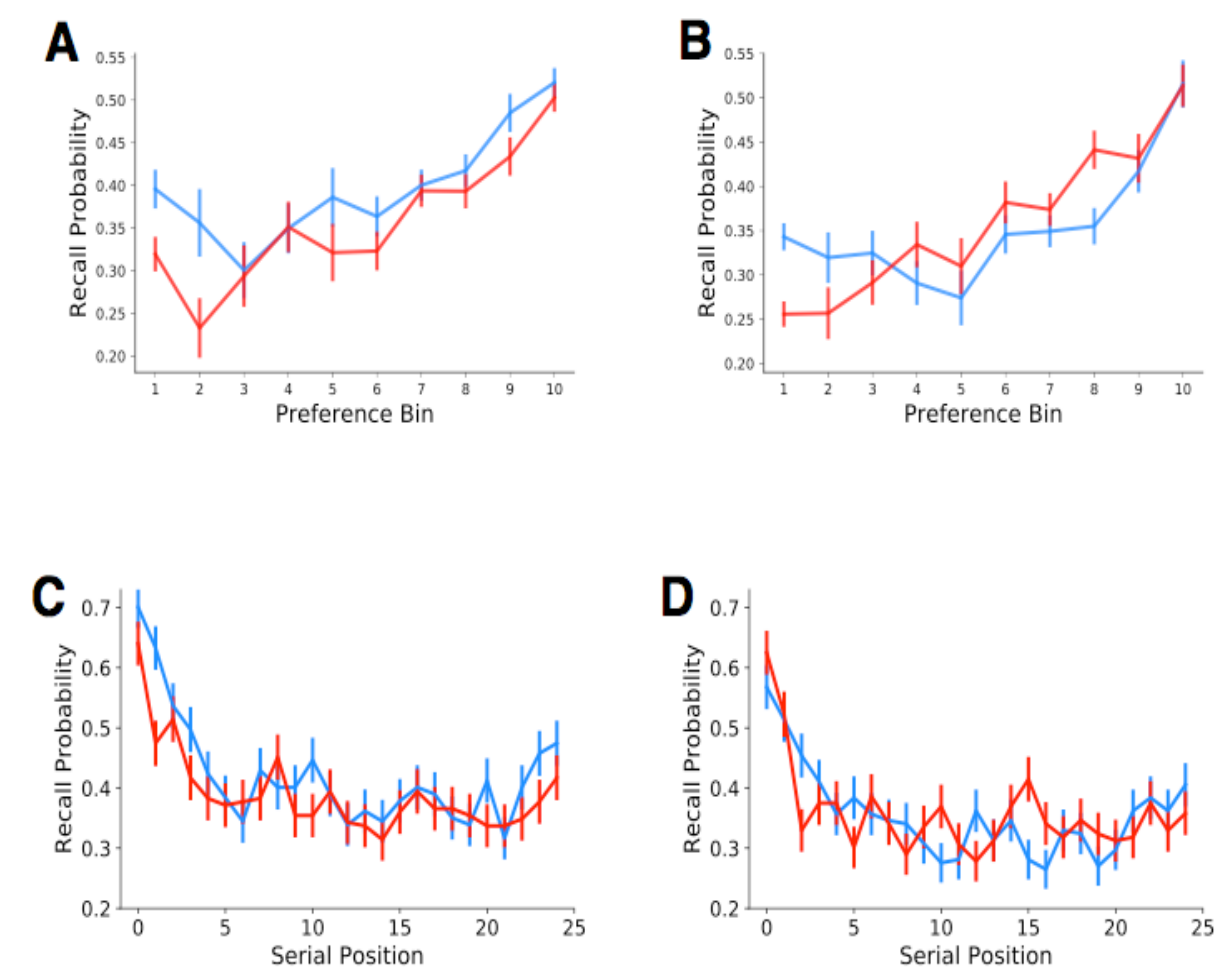

\section{Standard Recall}

\section{Choice-Directed Recall}

Figure 2. Influence of desirability on recall in Experiment 1 (Figure $2 \mathrm{~A}$ ) and in Experiment 2 (Figure $2 B$ ). We partitioned all possible desirability ratings into ten equally spaced bins (with bin 1 consisting of the set of items that received the lowest desirability ratings), and then plotted the aggregate probability of recall for items in each bin. Influence of encoding serial position on recall in Experiment 1 (Figure 2C) and in Experiment 2 (Figure 2D). Error bars are 干1 SEM.

Using mixed generalized linear models, we further explored the influence of desirability and serial position (operationalized as a quadratic effect) on recall, as well as the interaction of these variables with the recall task. Our regressions permitted random effects on the participant level. In Table S1, we see that both desirability and serial position had a significant effect, with higher recall probabilities for desirable items and items presented first and last in the list. 
Additionally, desirability had a significant interaction with task, suggesting that desirable (undesirable) items are more (less) likely to be remembered in choice-directed recall relative to standard recall.

The interaction of memory and desirability in our mixed models provides new insights about how preference effects can be incorporated into theories of memory retrieval. First, the finding that preferences play a role in even standard memory tasks (i.e. higher recall for desirable items) provides support for a bottom up influence of preference on memory. Second, the finding that this effect varies based on the task a participant is engaged in (bigger effect of preference in choice task) suggests a top-down influence of desirability, i.e. memory search guided or modulated by the participant's goal. The bottom-up influence is task independent, and would predict a main effect of preference on recall in our memory model, whereas the top-down influence is task dependent, and would predict an interaction effect between preference and task in our memory model. With our general model we can systematically test these effects, and rigorously incorporate preferences into existing memory models. We do this in the Memory Model section below.

\section{Determinants of Conditional Recall}

Another family of memory regularities involves the cued recall of items based on the temporal encoding sequence and semantic relationships among items. The effect of the encoding sequence generates temporal clustering, whereas the effect of semantic associations generates semantic clustering. Temporal clustering can be visualized by plotting the conditional recall probability (CRP) of items as a function of temporal association or lag (Howard \& Kahana, 2002; Kahana 1996). This is provided in Figures $3 A$ and $3 B$. Temporal clustering appears to have emerged in both our conditions, but is weaker in choice-directed recall relative to standard recall (especially for lags of $+1,+2$, and +3 ). In Figures $3 C$ and $3 D$, we plot similar CRP curves 
as a function of semantic associations. Although we observe a semantic clustering effect, the magnitude of this effect does not vary across conditions.

To systematically compare these effects in standard and choice-directed recall, we computed temporal and semantic clustering scores with the method developed by Polyn et al. (2009). Both temporal and semantic clustering scores range from 0 to 1 , and those scores greater than 0.50 are assumed to provide evidence for clustering effects in recall. Average semantic and temporal clustering scores in our two experiments are provided in Figures $3 E$ and $3 F$. Here, consistent with the CRP curves, we see that temporal clustering emerged in both standard and choice-directed recall, but was substantially weaker in the latter. Semantic clustering, in contrast, did not display this pattern (and in fact was slightly stronger in choice-directed recall relative to standard recall). A more rigorous analysis involves a mixed-effect regression of temporal and semantic clustering scores on the condition variable, with random effects on the participant-level. Results showed that temporal clustering was significantly weaker in choice-directed recall compared to standard recall in Experiment $1(\beta=-0.03,95 \% C I=[-0.05,-0.007], p=.012)$. Although this effect appears to emerge in Experiment 2, it does not cross the threshold for significance $(\beta=-0.03,95 \% C I=[-0.01,0.03], p=.075)$. In contrast, there was no difference in semantic clustering across the two conditions (both $\beta=0.008,95 \% C I s=[-0.01,0.03], p>.40)^{3}$.

\footnotetext{
${ }^{3}$ Additional details regarding our calculation of temporal and semantic clustering scores are provided in the Supplemental Materials.
} 

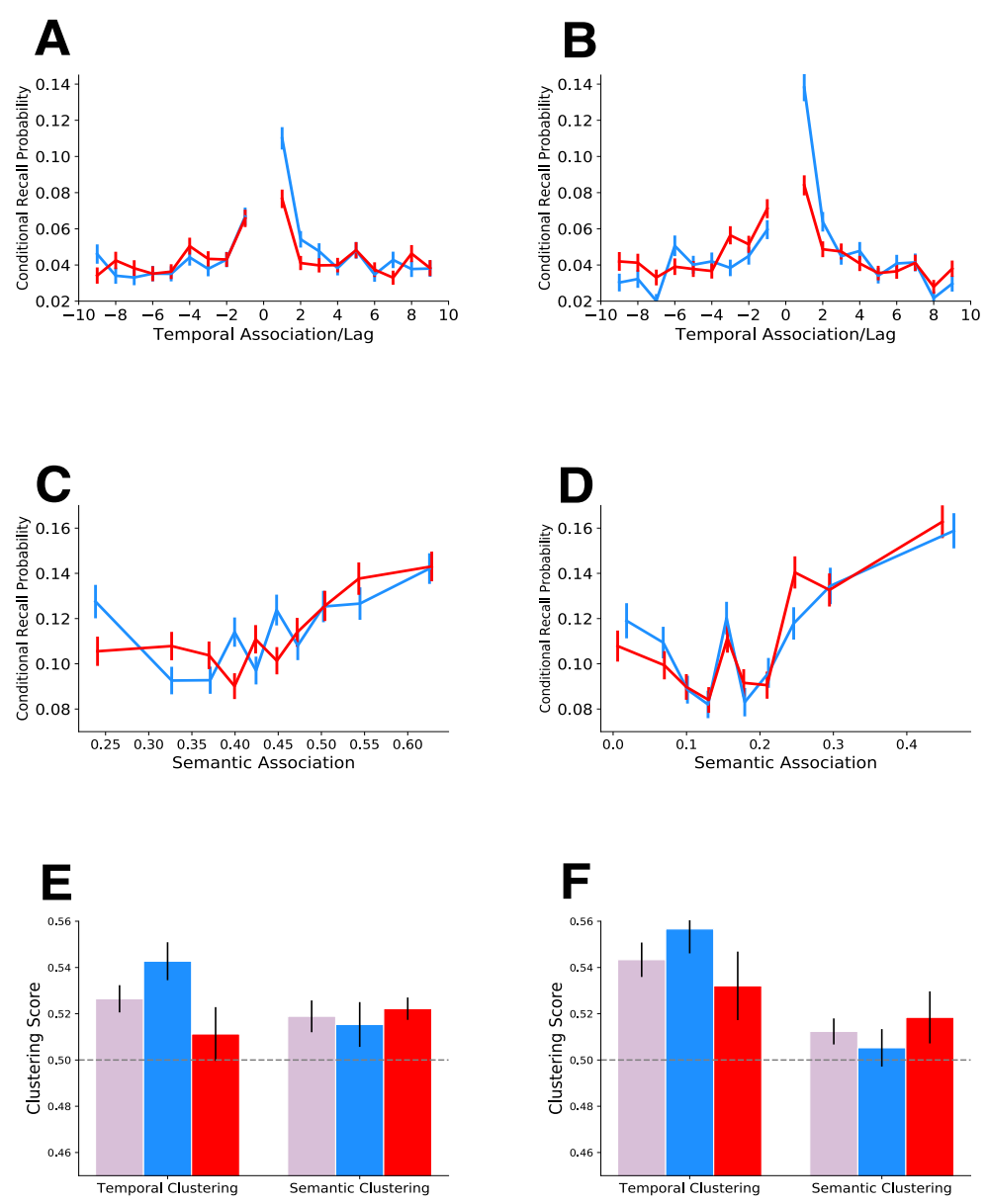

All Conditions

Standard Recall

Choice-Directed Recall

Figure 3. Temporal and semantic clustering in both experiments. Conditional recall probability (CRP) of items as a function of temporal association/lag in Experiment 1 (Figure $3 \mathrm{~A}$ ) and in Experiment 2 (Figure 3B). Here, a lag of $\mathrm{k}$ shows the probability of recalling an item presented $\mathrm{k}$ positions after (for positive $\mathrm{k}$ ) or before (for negative $\mathrm{k}$ ) a just-recalled item, and a higher CRP for small absolute lags indicates the emergence of temporal clustering. Conditional recall probability (CRP) of items as a function of semantic association in Experiment 1 (Figure $3 C$ ) and in Experiment 2 (Figure 3D). Here, a higher CRP for higher levels of semantic associations (i.e. positively sloped line) indicates that there is a larger probability of recalling an item that is highly similar to a just presented item, which is evidence for semantic clustering. Average temporal and semantic clustering scores in Experiment 1 (Figure 3E) and in Experiment 2 (Figure $3 F)$. Error bars are $\mp 1$ SEM. 


\section{Memory Model}

To examine all five of the memory regularities simultaneously, we used a computational memory model ${ }^{4}$. Our model assumed that the recall probability of an item at a particular time was given by its activation at that time, which in turn was a linear function of the item's desirability and serial position (operationalized as a quadratic effect), as well as its temporal association and semantic association with the previously recalled item. Starting activation was determined entirely by desirability and serial position (Figure 4). Recall probabilities were obtained by passing item activations through a logit link function. In our models, we added a dummy coded task variable to indicate which condition a participant was in (coded as 0 for the standard recall condition and as 1 for the choice-directed recall condition). Implicitly our model assumed that recall can be seen as a Markov random walk through the items in memory. Such a Markov assumption has been used to model memory search (e.g. Abbott et al., 2015; Healy, 1978; Bourgin et al., 2014) and is a simplified version of established memory models like the Context Retrieval and Maintenance Model and the Search of Associative Memory model (Polyn et al., 2009; Raaijmakers \& Shiffrin, 1980).

\footnotetext{
${ }^{4}$ Please see Supplemental Materials for details of our computational memory model.
} 


\begin{tabular}{|l|c|c|c|c|c|c|}
\hline \multicolumn{7}{|c|}{ An Example List } \\
\hline & Item 1 & Item 2 & Item 3 & Item 4 & $\ldots$ & Item 25 \\
\hline $\begin{array}{l}\text { Presented } \\
\text { Item }\end{array}$ & croissant & muffin & hamburger & cheeseburger & $\ldots$ & pizza \\
\hline $\begin{array}{l}\text { Desirability } \\
\text { Rating }\end{array}$ & 5 & 30 & 10 & 35 & $\ldots$ & 70 \\
\hline
\end{tabular}

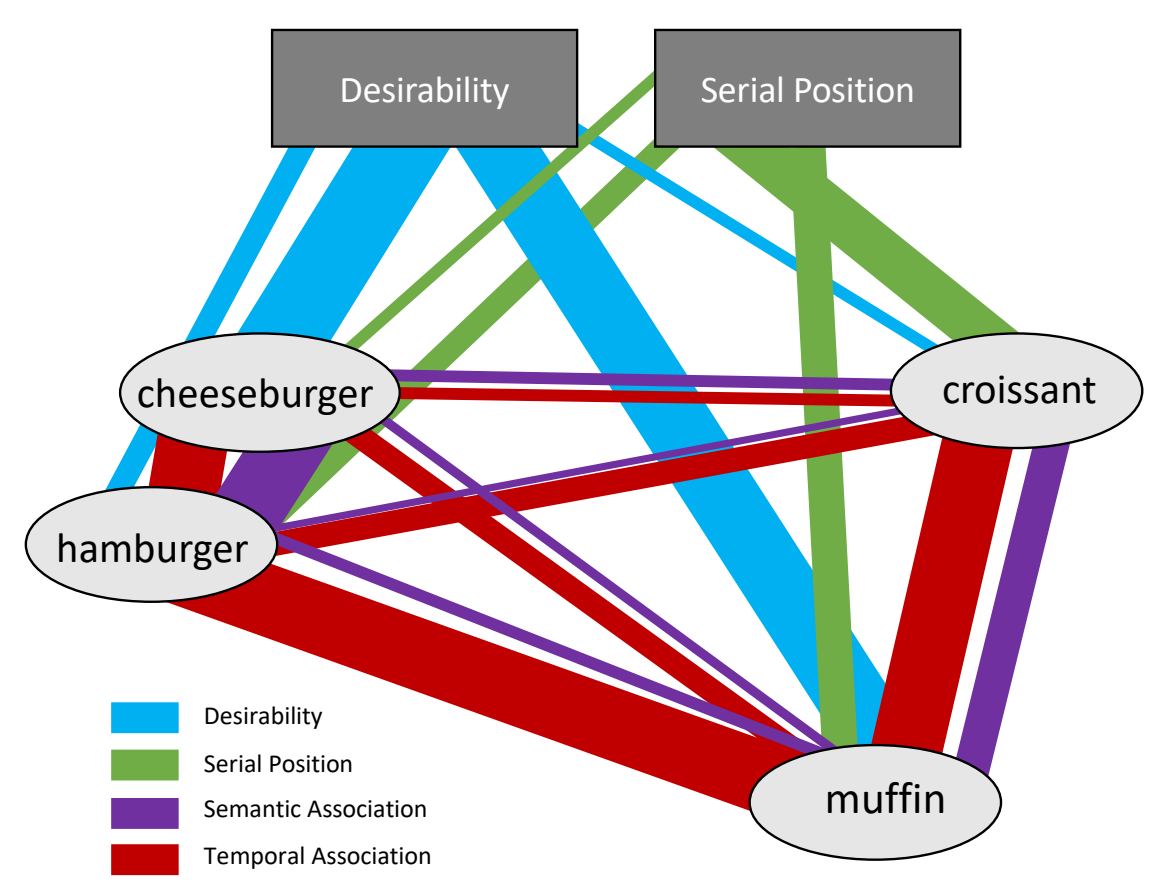

Figure 4. Representation of our computational memory model for an example list. While inputs to each item node are provided by the desirability ratings, serial position, temporal and semantic associations create the connections between the item nodes. Items with stronger temporal or semantic associations, as well as higher desirability ratings and items presented at the start or at the end of the list have thicker connection. Items with larger inputs have higher activation and are more likely to be recalled.

We fit our model to recall data in our two experiments using maximum likelihood estimation and each model was fit 100 times to ensure that the parameters stabilize. As part of our fits, we also added a task interaction term with each of the four variables (resulting in four distinct models, one for each variable) and conducted a likelihood ratio test between each model 
with an interaction term and a base model, to evaluate whether allowing for a change in the effect of the variables across the two tasks resulted in a superior fit. Our results, shown in Table 1 and Tables $S 2 A-B$, demonstrated that the desirability variable was significantly more influential for the choice-directed recall task in both experiments. Correspondingly, the temporal clustering variable was significantly less influential for the choice-directed recall. Our results also showed that primacy was slightly weaker in the choice-directed recall, though this difference did not reach significance.

\begin{tabular}{ccccccc}
\hline & \multicolumn{3}{c}{ Experiment 1 } & \multicolumn{3}{c}{ Experiment 2 } \\
Model & $\begin{array}{c}\text {-Log } \\
\text { Likelihood }\end{array}$ & $\begin{array}{c}\text { Chi- } \\
\text { Square }\end{array}$ & P-Value & $\begin{array}{c}\text {-Log } \\
\text { Likelihood }\end{array}$ & $\begin{array}{c}\text { Chi- } \\
\text { Square }\end{array}$ & P-Value \\
\hline Base Model & 19,932 & & & 18,000 & & \\
w/ Desirability * Task & 19,927 & 8.87 & .003 & 17,956 & 87.20 & $<.001$ \\
w/ Serial Position * Task & 19,931 & 1.36 & 0.244 & 17,998 & 2.56 & .11 \\
w/ Temp. C. * Task & 19,925 & 12.82 & $<.001$ & 17,996 & 7.32 & .007 \\
w/ Sem. C. * Task & 19,932 & 0.13 & .708 & 17,999 & 0.60 & .439 \\
\hline
\end{tabular}

Table 1. Comparisons between models with task-based interactions with the variables, and the base model without task-based interactions. The chi-square values involve log-likelihood differences between the base model and each of the remaining models, and indicate whether or not adding the task-based interaction for that variable results in superior fits.

While the influence of temporal clustering can only appear when people are transitioning from one item to another, desirability may be influential both for the first recall and in the transitions between subsequent recalls. Using our computational model, we were able to disentangle these two potential effects of desirability by having separate weights corresponding to the mechanisms that are in play for starting activations and transition activations. In the supplemental materials we use this method to show that desirability does not only differentially influence memory at the beginning of retrieval, but also persists as a consistent effect while participants continue to remember more items during choice-directed recall. In other words, 
memory-based choice involves differences in both starting points and transitions, relative to standard recall.

\section{Discussion}

The importance of memory for preferential decision making is well understood. Yet little is known about the nature and magnitude of established memory phenomena during decision making, and how they relate to memory processes in standard memory tasks. This report is the first to attempt a systematic examination of memory effects in standard recall and choicedirected recall. It has done so using a variant of the classical list learning paradigm, and has found evidence that traditional memory regularities such as the serial position effects, and the semantic and temporal clustering effects, persist during decision making. In addition, it has found that desirability plays an important role in both tasks. Critically, desirability is more pronounced and temporal clustering is less pronounced in choice-directed recall, suggesting that preferential choice modulates memory by activating choice-relevant features of items, and diminishing the influence of other elements of memory organization, such as temporal structure.

The results from our standard recall condition are consistent with the vast literature on list learning (e.g., Romney, Brewer, \& Batchelder, 1993; Kahana, 1996; Kahana, 2017). We find strong primacy effects, as well as weaker recency effects, which is typical in memory studies that include a distractor task in between study and recall of list items (e.g., Sederberg, Howard, \& Kahana, 2008; Glanzer \& Cunitz, 1966; Postman \& Phillips, 1965). ${ }^{5}$ These results also support recent research on value-directed remembering that finds that the values of items serve as important cues during retrieval (Castel, 2007; Hennessee et al., 2019; Friedman, McGillivray, Murayama, \& Castel, 2015; Stefanidi, Ellis, \& Brewer, 2018). Unlike experiments within this

\footnotetext{
${ }^{5}$ In our study, the surprise task instructions may have served as a distractor task, weakening the recency effects.
} 
paradigm, we do not assign objective values to items during encoding, but rather analyze the effect of subjective desirability on retrieval. Yet consistent with this paradigm, our results indicate that desirable (i.e. high value) items are more likely to be recalled. Our key finding is that this tendency is more pronounced during choice, which suggests that the metacognitive mechanisms known to be at play in value-directed remembering may be also be active during memory-based choice. Using our computational approach, we were also able to document both bottom-up (task-independent) and top-down (task-dependent) influences of preferences on memory, which shed light on how preferences and memory interact. Future work should build off these results to integrate these two distinct areas of research in psychology.

One key aspect of our paradigm is that we did not have any encoding manipulations across participants in different conditions; as we asked all participants to simply study the presented items without any information regarding the type of the task to follow. The retrieval task, however, was manipulated based on whether a participant was in the standard recall or choice-directed recall task condition. Thus, our results control for encoding differences and provide strong support for the modulation of memory based on the retrieval task one is engaged in. Our experimental paradigm offers an empirical framework for comparing memory in choice vs. standard recall, and future work could use it to study encoding differences in the two domains as well.

Our work is notable for its use of computational memory models to characterize the retrieval process, and quantify differences between memory-based decision making and standard recall. By showing that desirability has a larger effect during preferential choice, our tests open the way for more extensive models of memory-based decision making, that explicitly specify top-down control processes for modulating recall. We would like to mention that while more complex computational memory models such as the Context Maintenance and Retrieval Model 
(CMR) (Polyn et al., 2009) may better describe the memory processes, our model allows us to conveniently and tractably measure the role of our predictor variables in a small dataset. These complex models would allow for violations of the Markov property and include psychologically nuanced ways of accommodating different regularities such as the (weak) recency effects. Taken together, further characterizing the nature of control and memory modulation in preferential choice, in order to build joint models of memory and decision making, is a promising topic for future work.

Our results also shed light on the adaptive value of memory in decision making (Anderson \& Shackleton, 1990; Gigerenzer \& Todd, 1999; Oaksford \& Chater, 2007; Simon, 1990). Cuing desirable items for recall in preferential choice tasks almost certainly speeds up the decision. The ability of decision makers to modulate memory also suggests that choice is far less prone to error than would be expected if memory was searched at random. Future work could build on our approach to rigorously measure the speed and accuracy gains generated by the memory mechanisms at play in choice-directed recall. At a broader level, our findings suggest that decision making processes can be interpreted as "selective" recall in the service of a goal. This is in contrast to a standard memory task involves an "exhaustive" recall mechanism. In this sense, our results imply that goal-directed recall in decision making involves the increased use of decision relevant features, and the decreased use of temporal congruence and related episodic features. Future work can test whether memory modulation in choice is cognitively effortful, as would be predicted by a goal-directed, or top-down, mechanism. This work can also test the degree to which our observed findings (e.g. reduction in temporal clustering) persist in other goal-directed recall settings. Finally, by relating retrieval dynamics in preferential choice to established processes and behavioral patterns in memory research, our research provides modelderived insights regarding behavioral interventions for improving recall during decision making. 
We look forward to future research that applies theories from both memory and decision making research to influence and improve the choices of individuals.

\section{Context of the Research}

The current research was formed as a project linking the main interests of the authors. While the first author has previous work concentrating on episodic memories and memorability using experimental paradigms similar to those in the current paper, the last author has extensive work examining decision making processes using computational methods. The current studies unite and extend these research interests by borrowing techniques from the memory literature and developing computational models to inform decision making theory. Future work will

further examine ways in memory models can be combined with decision models, to better inform our understanding the cognitive basis of decision making. 


\section{References}

Anderson, J. R. (1993). Rules of the mind. Hillsdale, NJ: Lawrence Erlbaum Associates, Inc.

Anderson, N., \& Shackleton, V. (1990). Decision making in the graduate selection interview: A field study. Journal of Occupational Psychology, 63(1), 63-76.

Bhatia, S. (2019). Semantic processes in preferential decision making. Journal of Experimental Psychology: Learning, Memory, and Cognition, 45(4), 627.

Biehal, G., \& Chakravarti, D. (1982). Information-presentation format and learning goals as determinants of consumers' memory retrieval and choice processes. Journal of Consumer Research, 8(4), 431-441.

Bornstein, A. M., \& Norman, K. A. (2017). Reinstated episodic context guides sampling-based decisions for reward. Nature Neuroscience, 20(7), 997.

Bourgin, D., Abbott, J., Griffiths, T., Smith, K., \& Vul, E. (2014). Empirical evidence for markov chain monte carlo in memory search. In Proceedings of the Annual Meeting of the Cognitive Science Society (Vol. 36, No. 36).

Carpenter, A. C., \& Schacter, D. L. (2018). False memories, false preferences: Flexible retrieval mechanisms supporting successful inference bias novel decisions. Journal of Experimental Psychology: General, 147(7), 988-1004.

Dougherty, M. R., Gettys, C. F., \& Ogden, E. E. (1999). MINERVA-DM: A memory processes model for judgments of likelihood. Psychological Review, 106(1), 180.

Friedman, M. C., McGillivray, S., Murayama, K., \& Castel, A. D. (2015). Memory for medication side effects in younger and older adults: The role of subjective and objective importance. Memory \& cognition, 43(2), 206-215.

Gigerenzer, G., \& Goldstein, D. G. (1999). Betting on one good reason: The take the best heuristic. In Simple heuristics that make us smart (pp. 75-95). Oxford University Press. 
Gigerenzer, G., \& Todd, P. M. (1999). Fast and frugal heuristics: The adaptive toolbox. In Simple heuristics that make us smart (pp. 3-34). Oxford University Press.

Glanzer, M., \& Cunitz, A. R. (1966). Two storage mechanisms in free recall. Journal of verbal learning and verbal behavior, 5(4), 351-360.

Healey, M. K. (2018). Temporal contiguity in incidentally encoded memories. Journal of Memory and Language, 102, 28-40.

Healy, A. F. (1978). A Markov model for the short-term retention of spatial location information. Journal of Verbal Learning and Verbal Behavior, 17(3), 295-308.

Hertwig, R., Barron, G., Weber, E. U., \& Erev, I. (2004). Decisions from experience and the effect of rare events in risky choice. Psychological Science, 15, 534-539. http://dx.doi.org/10.1111/j.0956-7976.2004 .00715.x

Hintzman, D. L. (2016). Is memory organized by temporal contiguity?. Memory \& Cognition, $44(3), 365-375$.

Howard, M. W., \& Kahana, M. J. (2002). A distributed representation of temporal context. Journal of Mathematical Psychology, 46(3), 269-299.

Hutchinson, J. W., Raman, K., \& Mantrala, M. K. (1994). Finding choice alternatives in memory: Probability models of brand name recall. Journal of Marketing Research, 31(4), 441-461.

Jeffreys, H. (1961). Theory of probability, 3rd edn oxford: Oxford university press.

Johnson, E. J., Häubl, G., \& Keinan, A. (2007). Aspects of endowment: a query theory of value construction. Journal of experimental psychology: Learning, memory, and cognition, 33(3), 461.

Kahana, M. J. (1996). Associative retrieval processes in free recall. Memory \& cognition, 24(1), 103-109. 
Kahana, M. J. (2017). Memory search. In J. H. Byrne (Ed.), Learning and Memory: A Comprehensive Reference, 2nd Edition (Second Edition $\backslash \mathrm{BEd}$, vol. 2, p. 181-200). Oxford: Academic Press.

Kahana, M. J., \& Miller, J. F. (2013). Memory, recall dynamics. Encyclopedia of the mind. Thousand Oaks, CA SAGE Publications Inc.

Kardes, F. R., Kalyanaram, G., Chandrashekaran, M., \& Dornoff, R. J. (1993). Brand retrieval, consideration set composition, consumer choice, and the pioneering advantage. Journal of Consumer Research, 20(1), 62-75.

Klein, K. A., Addis, K. M., \& Kahana, M. J. (2005). A comparative analysis of serial and free recall. Memory \& Cognition, 33(5), 833-839.

Kruschke, J. K. (2013). Bayesian estimation supersedes the $\mathrm{t}$ test. Journal of Experimental Psychology: General, 142(2), 573.

Leding, J. K. (2019). Intentional memory and online data collection: A test of the effects of animacy and threat on episodic memory. Journal of Cognitive Psychology, 31(1), 4-15.

Li, C. (2010). Primacy effect or recency effect? A long-term memory test of Super Bowl commercials. Journal of Consumer Behaviour: An International Research Review, 9(1), $32-44$.

Ludvig, E. A., Madan, C. R., \& Spetch, M. L. (2015). Priming memories of past wins induces risk seeking. Journal of Experimental Psychology: General, 144(1), 2429. http://dx.doi.org/10.1037/xge0000046

Madan, C. R., Fujiwara, E., Gerson, B. C., \& Caplan, J. B. (2012). High reward makes items easier to remember, but harder to bind to a new temporal context. Frontiers in Integrative Neuroscience, 6, 61. 
Manning, J. R., \& Kahana, M. J. (2012). Interpreting semantic clustering effects in free recall. Memory, 20(5), 511-517.

Murty, V. P., FeldmanHall, O., Hunter, L. E., Phelps, E. A., \& Davachi, L. (2016). Episodic memories predict adaptive value-based decision-making. Journal of Experimental Psychology: General, 145(5), 548.

Nedungadi, P., Chattopadhyay, A., \& Muthukrishnan, A. V. (2001). Category structure, brand recall, and choice. International Journal of Research in Marketing,18(3), 191-202. https://doi.org/10.1016/S0167-8116(00)00028-8

Oaksford, M., \& Chater, N. (2007). Bayesian rationality: The probabilistic approach to human reasoning. Oxford University Press.

Polyn, S. M., Norman, K. A., \& Kahana, M. J. (2009). A context maintenance and retrieval model of organizational processes in free recall. Psychological review, 116(1), 129.

Postman, L., \& Phillips, L. W. (1965). Short-term temporal changes in free recall. Quarterly journal of experimental psychology, 17(2), 132-138.

Raaijmakers, J. G., \& Shiffrin, R. M. (1980). SAM: A theory of probabilistic search of associative memory. In Psychology of learning and motivation (Vol. 14, pp. 207-262). Academic Press.

Romney, A. K., Brewer, D. D., \& Batchelder, W. H. (1993). Predicting clustering from semantic structure. Psychological Science, 4(1), 28-34.

Schooler, L. J., \& Hertwig, R. (2005). How forgetting aids heuristic inference. Psychological Review, 112(3), 610-628. http://dx.doi.org/10.1037/0033-295X. 112.3.

Sederberg, P. B., Howard, M. W., \& Kahana, M. J. (2008). A context-based theory of recency and contiguity in free recall. Psychological review, 115(4), 893. 
Sederberg, P. B., Miller, J. F., Howard, M. W., \& Kahana, M. J. (2010). The temporal contiguity effect predicts episodic memory performance. Memory \& cognition, 38(6), 689-699.

Sherrick, B., Dardis, F. E., Bailey, E., Aviles, J., Schmierbach, M., Kumble, S., \& Waddell, F. (2016). Adver-Where? Comparing the Effectiveness of Banner Ads and Video Ads in Online Video Games. Journal of Interactive Advertising, 16(2), 87-100.

https://doi.org/10.1080/15252019.2016.1223572

Shohamy, D., \& Daw, N. D. (2015). Integrating memories to guide decisions. Current Opinion in Behavioral Sciences, 5, 85-90.

Simon, H. A. (1990). Bounded rationality. In Utility and probability (pp. 15-18). Palgrave Macmillan, London.

Stefanidi, A., Ellis, D. M., \& Brewer, G. A. (2018). Free recall dynamics in value-directed remembering. Journal of Memory and Language, 100, 18-31.

van Doorn, J., van den Bergh, D., Bohm, U., Dablander, F., Derks, K., Draws, T., ... \& Ly, A. (2019). The JASP guidelines for conducting and reporting a Bayesian analysis.

Ward, G., Tan, L., \& Grenfell-Essam, R. (2010). Examining the relationship between free recall and immediate serial recall: The effects of list length and output order. Journal of Experimental Psychology: Learning, Memory, and Cognition, 36(5), 1207.

Weber, E. U., Böckenholt, U., Hilton, D. J., \& Wallace, B. (1993). Determinants of diagnostic hypothesis generation: Effects of information, base rates, and experience. Journal of Experimental Psychology: Learning, Memory, and Cognition, 19, 1151-1164. http://dx.doi.org/10 .1037/0278-7393.19.5.1151

Weber, E. U., Johnson, E. J., Milch, K. F., Chang, H., Brodscholl, J. C., \& Goldstein, D. G. (2007). Asymmetric Discounting in Intertemporal Choice: A Query-Theory Account. 
Psychological Science, 18(6), 516-523. https://doi.org/10.1111/j.14679280.2007.01932.x 


\section{Supplemental Materials}

Aka and Bhatia (2020)

\section{Methods}

\section{Participants}

Participants $(N=352$; mean age $=33 ; 52 \%$ female $)$ in Experiment 1 and participants in Experiment $2(N=361$; mean age $=34 ; 49 \%$ female $)$, recruited from Prolific Academic, performed the experiment online. Power analyses (with the goal of obtaining .80 power at the standard .05 alpha error probability) were computed to determine the number of study participants. All participants were residents of the United States and English was their native language. They were compensated at a rate of approximately $\$$ US 7.50/hr. Our experiments were approved by the University of Pennsylvania Institutional Review Board (IRB).

\section{Stimuli}

Experiment 1 had a word pool of 50 food items such as "pizza" and "gumbo" from which each participant was presented with a randomly selected set of 25 items. Study 2 had a fixed word pool of 25 gift items, such as "bracelet" and "puzzle", from which the items were presented in a random order. The full list of items in each word pool can be found at the bottom of this Supplemental Materials document.

\section{Full Procedure}

In order to ensure that differences between our conditions were not due to biased encoding, participants in both conditions were first shown a list composed of twenty-five items drawn from the experiment's word pool. These were food items in Experiment 1 and gift items in Experiment 2. Words were presented one after another in the center of the screen in black text 
on a white background for $1600 \mathrm{~ms}$. Participants were told to study the items carefully as they would be asked questions about the items in subsequent screens (but were not told what these questions would entail).

The key manipulation of our studies was the recall prompt that participants were shown before retrieving items from their memory. At the end of the list, participants in the standard recall condition were asked to list the words from the list that come their minds, in any order, and type those words in the boxes provided one after another. These participants' recall prompt read:

"In the next few screens you will be asked to list items from the just presented list. Please list these items one after another in the order that they come to your mind (i.e., the first item that comes to your mind listed on the first screen, the second listed on the second, etc.) You can repeat items, that is, you can list an item multiple times if the same item comes to your mind repeatedly. We would like you to list all the items that come to your mind. Please leave the box empty once you run out of items to list."

Similarly, participants in the choice-directed recall condition were asked to list items that come to their minds while they deliberate on what they will eat tomorrow (Study 1), or what item will they gift to their friend (Study 2). The choice-directed recall condition participants' prompt in each of the studies read:

Experiment 1. "Imagine that you are deciding on what you will eat tomorrow, and that you have to choose one of the items from the just presented list. In the next few screens you will be asked to list items that come to your mind as you deliberate. Please list these items one after another in the order that they come to your mind (i.e., the first item that comes to your mind listed on the first 
screen, the second listed on the second, etc.) You can repeat items, that is, you can list an item multiple times if the same item comes to your mind repeatedly. We would like you to list all the items that come to your mind, even if you would not choose to eat them. Please leave the box empty once you run out of items to list."

Experiment 2. "Imagine that you are deciding on what you will give your friend as a gift, and that you have to choose one of the items from the just presented list. Please note that the presented gift items have the same price. In the next few screens you will be asked to list items that come to your mind as you deliberate. Please list these items one after another in the order that they come to your mind (i.e., the first item that comes to your mind listed on the first screen, the second listed on the second, etc.) You can repeat items, that is, you can list an item multiple times if the same item comes to your mind repeatedly. We would like you to list all the items that come to your mind, even if you would not choose to gift them. Please leave the box empty once you run out of items to list."

After listing the items, choice-directed recall participants were also asked to indicate which single item they would choose, though this data was not examined in the present study.

In both conditions, participants were allowed to list an item multiple times if the same item came to their mind repeatedly. Although repetitions are not commonly allowed in standard list recall tasks, they may serve as important memory cues in choice, which is why we allowed for repetitions in both our conditions. For a similar reason we did not ask participants in the standard recall condition to try to exhaustively list all items: They were simply asked to list all the items that came to their minds. We likewise asked participants in the choice-directed recall 
condition to list all items that came to their minds even if they would not choose the items in the choice task.

Next, all participants were taken to a page in which they rated the word pool items. Specifically, each participant rated the desirability of each item for eating or giving as a gift on a scale from -50 to 50 . Participants also rated how frequently they consumed/gifted each of the items on a scale from -50 to 50 . These desirability and frequency of consumption rating questions were presented to all participants at the end of the study, in a randomized order.

\section{General Recall Pattern Results}

\section{Results}

To systematically investigate the number of unique words remembered across conditions in both of our studies, we computed 95\% Highest Density Intervals (HDIs) and conducted Bayesian t-tests for the difference between the means. We computed 95\% HDIs following the steps outlined by Kruschke (2013). These intervals included zero in Experiment 1 (95\% HDI: [-1.03, 0.955]) and in Experiment 2 (95\% HDI: [-0.995, 0.956]). We next conducted a Bayesian t-test using framework proposed by Jeffreys (1961, see also Rouder et al. 2009). We analyzed the data with JASP (JASP Team, 2019). The null hypothesis postulates that there is no difference in the number of unique words remembered between the standard recall and choice-directed recall conditions and therefore $\mathrm{H}_{0}: \delta=0$. The two-sided alternative hypothesis states that there is a difference in the number of unique words remembered across conditions. In our analysis, $\delta$ was assigned the default Cauchy prior distribution and the Bayes factor from the t-test indicates slight evidence for $\mathrm{H}_{0}$; specifically, $\mathrm{BF}_{01}=1.744$ in Experiment 1 and $\mathrm{BF}_{01}=8.54$ in Experiment 2 . These Bayes factors mean that the data are approximately 1.744 and 8.54 times more likely to occur under $\mathrm{H}_{0}$ than under $\mathrm{H}_{+}$in Experiment 1 and Experiment 2, subsequently. This result 
indicates moderate evidence in favor of $\mathrm{H}_{0}$. The error percentage is $<0.001 \%$ in both cases, which indicates great stability of the numerical algorithm that was used to obtain the result.

While the analyses conducted to examine the general recall patterns were exploratory, all other analyses reported in this paper were pre-registered.

\section{Computing the Temporal and Semantic Clustering Scores}

We computed temporal and semantic clustering scores with the method developed by Polyn, Norman, and Kahana (2009). These scores are intended to quantify the extent to which a given recall sequence shows evidence for temporal or semantic clustering based on the sequence of presented and recalled words in the study list. In order to calculate semantic clustering scores, we took the following steps. Using pre-trained semantic vectors generated with the word $2 \mathrm{vec}$ model (Mikolov et al., 2013), we first computed the cosine distance between the vector representations of every word-pair in the word pool. Next, we calculated a distribution of semantic association values between the just-recalled word and all of the other words that could be recalled. Please note that while Polyn et al. (2009) restricted this step to only include semantic association values between the just-recalled word, and the set of words that have not yet been recalled, our study permitted repetitions, and thus we did not impose this restriction. Finally, we computed a percentile score by comparing the generated semantic association value corresponding to the next recalled item observed in the participant's recall sequence to the rest of the distribution. We also computed the temporal clustering scores using these steps. However, instead of using the semantic distances, this time we used the temporal distances between words in the presented list (i.e. the absolute value of the difference between the serial position of the just-recalled word and the set of all other words that could be recalled). 
Both temporal and semantic clustering scores range from 0 to 1 . In these studies, 0 indicates that the participant always recalls (from the set of possible items to choose) the farthest temporal distance or weakest semantic associate. No effect of temporal or semantic clustering is signified by 0.5 , while 1 indicates that the participant always recalls the closest temporal distance or strongest semantic associate, representing perfect memory organization.

\section{Mixed Generalized Linear Models}

Using mixed generalized linear models, we further explored the influence of desirability and serial position (operationalized as a quadratic effect) on recall, as well as the interaction of these variables with the task (Table S1). To be more specific, in these regressions, our dependent variable was whether each word is remembered or not. The desirability and serial position variables that vary for each word, as well as the task condition, and their interaction served as the predictor variables. Our regressions permitted random effects on the participant level.

\begin{tabular}{lrrrr} 
Model for Desirability & \multicolumn{2}{c}{ Experiment 1 } & \multicolumn{2}{c}{ Experiment 2 } \\
\hline Estimate & $\boldsymbol{\beta}$ & $\mathbf{9 5 \%} \boldsymbol{C I}$ & $\boldsymbol{\beta}$ & \multicolumn{1}{c}{$\mathbf{9 5 \%} \boldsymbol{C I}$} \\
\hline Intercept & $-0.42^{* * *}$ & {$[-0.53,-0.31]$} & $-0.65^{* * *}$ & {$[-0.78,-0.52]$} \\
Desirability & $0.007 * * *$ & {$[0.005,0.01]$} & $0.006^{* * *}$ & {$[0.004,0.008]$} \\
Task & $-0.18^{*}$ & {$[-0.34,-0.03]$} & 0.02 & {$[-0.16,0.21]$} \\
Desirability * Task & $0.003^{*}$ & {$[-0.00,0.006]$} & $0.008^{* * *}$ & {$[0.005,0.01]$} \\
\hline
\end{tabular}

\begin{tabular}{lrrrr} 
Model for Serial Position & \multicolumn{2}{c}{ Experiment 1 } & \multicolumn{2}{c}{ Experiment 2 } \\
\hline Estimate & $\boldsymbol{\beta}$ & $\mathbf{9 5 \%} \boldsymbol{C I}$ & $\boldsymbol{\beta}$ & \multicolumn{1}{c}{$\mathbf{9 5 \%} \boldsymbol{C I}$} \\
\hline Intercept & $0.54^{* * *}$ & {$[0.35,0.73]$} & 0.14 & {$[-0.06,0.35]$} \\
Serial Position & $-0.17^{* * *}$ & {$[-0.20,-0.13]$} & $-0.16^{* * *}$ & {$[-0.20,-0.13]$} \\
Serial Position & $2.006^{* * *}$ & {$[0.004,0.007]$} & $0.006^{* * *}$ & {$[0.004,0.007]$} \\
Task & $-0.38^{* *}$ & {$[-0.65,-0.11]$} & -0.19 & {$[-0.48,-0.11]$} \\
Serial Position $*$ Task & $0.05^{*}$ & {$[0.005,0.10]$} & 0.05 & {$[-0.00,0.10]$} \\
Serial Position $^{2}$ Task & $-0.002^{*}$ & {$[-0.004,-0.00]$} & -0.002 & {$[-0.004,-0.00]$} \\
\hline
\end{tabular}
$* p<.05, * * p<.01, * * * p<.001$

Table S1. Experiments 1 and 2 separate mixed effects model coefficients. Confidence intervals are calculated using a nonparametric bootstrapping procedure. 


\section{Model Specifications}

We generated a Markov chain process model to fit data from participants' word transitions. Let $X(t)$ be the random variable which describes the 'state' of a given individual at time $t$. For the purposes of this paper we assumed $X(t)$ was discrete and t only $k=25$ distinct values, one referring to each of the words in the word pool (i.e., "pizza", "gumbo"). With this notation, the probability of moving from state $i$ to state $j$ at time $t$ can be expressed as:

$$
p_{i j}(t)=\operatorname{Pr}(X(t)=j \mid X(t-1)=i)
$$

The overall set of transition probabilities between states (or words) can be organized in a $25 \times 25$

transition matrix, $\mathrm{M}_{\mathrm{t}}=\left[p_{i j}(t)\right]$, with $\sum_{j=1}^{25} P_{i j}(t)=1, \forall i, j, t$ (the probabilities in the row must sum to 1$)$.

We were interested in understanding the similarities and differences between memory regularities (desirability, serial position, serial position ${ }^{2}$, temporal clustering, and semantic clustering) in standard recall and choice-directed recall. In our computational memory model, we assumed that the recall probability of an item at a particular time was given by its activation at that time, which in turn was a linear function of the item's desirability, serial position, and serial position $^{2}$, as well as its temporal association and semantic association with the previously recalled item. Temporal association was defined as the absolute value lag distance between the serial positions in the presented list, of the word recalled at time $t$ and time $t+1$. Semantic association was specified using cosine similarity in the word2vec. Desirability was defined by the preference ratings each participant provided for each item at the end of the study (these ratings initially ranged from -50 to 50 , but 50 was added to each of rating in the memory model to have ratings that range from 0 to 100). Serial position was defined by the serial position the 
item was presented in (ranging from 0 to 24 ), and serial position ${ }^{2}$ was the quadratic term for serial position by squaring the serial position number.

In our models, we added a dummy coded task variable to indicate which condition a participant was in (coded as 0 for the standard recall condition and as 1 for the choice-directed recall condition). Subsequently the activation for an item $j$ at time $t$, given that item $i$ had been recalled at $t-1$ was:

$$
\begin{aligned}
& A_{i j}(t)=\beta_{D} * \text { Desirability } j+\beta_{P} * \text { Serial Position } j+\beta_{R} * \text { Serial Position }^{2} j+ \\
& \beta_{\text {Temp }} * \text { Temporal Association } i j+\beta_{\text {Sem }} * \text { Semantic Association } i j+\beta_{C} * \text { Task }
\end{aligned}
$$

The starting activation of an item $i$ at time 0 was also given by the equation above, except that both temporal association and semantic association were set to 0 . Thus, it was only a function of desirability, serial position, and serial position ${ }^{2}$. As our dependent variable was binary (i.e. each word is remembered or not), we passed item activations through a logistic link to determine recall probabilities.

$$
P_{i j}(t)=\operatorname{logit}(\text { Propensity summed and exponentiated over all } j)=\frac{e^{A_{i j}(t)}}{\sum_{k=1}^{N} e^{A_{k j(t)}}}
$$

We fit our model using maximum likelihood estimation (with Nelder-Mead method) in Python and each model was fit 100 times to ensure that the parameters stabilize. After fitting the full model, we also added a task interaction term with each of the five variables (resulting in five distinct models, one for each variable). For example, the model that included a task interaction with the semantic association variable had the following transition activations:

$$
\begin{aligned}
& \quad \mathrm{A}_{\mathrm{ij}}(\mathrm{t})=\beta_{D} * \text { Desirability } j+\beta_{P} * \text { Serial Position } j+\beta_{R} * \text { Serial Position }{ }^{2} j+ \\
& \beta_{\text {Temp }} * \text { Temporal Association } i j+\beta_{\text {Sem }} * \text { Semantic Associations } i j+\beta_{C} * \text { Task }+ \\
& \beta_{\text {Sem } * \text { Task }} * \text { Semantic Association } i j * \text { Task }
\end{aligned}
$$


Next, we conducted a likelihood ratio test between each model with an interaction term and a base model without the interaction term, to evaluate whether allowing for a change in the effect of the variables across the two tasks resulted in a superior fit. Model coefficients, likelihoods, and results of the likelihood ratio tests are reported in Tables $2 A-B$.

\begin{tabular}{lcccccccc}
\hline & & Serial & $\begin{array}{c}\text { Serial } \\
\text { Position } \\
\text { Squared }\end{array}$ & $\begin{array}{c}\text { Temp. } \\
\text { C. }\end{array}$ & $\begin{array}{c}\text { Sem. } \\
\text { C. }\end{array}$ & Task & $\begin{array}{c}\text { Task } \\
\text { Interaction(s) }\end{array}$ & -LL \\
\hline Base Model & 0.01 & -0.11 & 0.004 & -0.04 & 1.57 & -0.03 & & 19,932 \\
Desirability * Task & 0.01 & -0.11 & 0.004 & -0.04 & 1.56 & 12.07 & 0.003 & $19,927 * * *$ \\
Serial Pos. * Task & 0.01 & -0.12 & 0.004 & -0.04 & 1.57 & -17.09 & $0.01 \&-0.0004$ & 19,931 \\
Temp. C. * Task & 0.01 & -0.11 & 0.00 & -0.04 & 1.56 & -7.45 & 0.02 & $19,925 * * *$ \\
Sem. C. * Task & 0.01 & -0.11 & 0.004 & -0.04 & 1.51 & -16.43 & 0.11 & 19,932 \\
\hline
\end{tabular}

*** Model with the interaction term has a significantly better fit than the model without the interaction term, $\chi 2(1)<8.87, p<.003$.

Table S2A. Experiment 1 Markov Chain process model coefficients.

\begin{tabular}{|c|c|c|c|c|c|c|c|c|}
\hline & Desirability & $\begin{array}{c}\text { Serial } \\
\text { Position }\end{array}$ & $\begin{array}{c}\text { Serial } \\
\text { Position } \\
\text { Squared }\end{array}$ & $\begin{array}{c}\text { Temp. } \\
\text { C. }\end{array}$ & Sem. C. & Task & $\begin{array}{c}\text { Task } \\
\text { Interaction }\end{array}$ & $-\mathbf{L L}$ \\
\hline Base Model & 0.01 & -0.13 & 0.004 & -0.04 & 1.60 & 0.07 & & 18,000 \\
\hline Desirability * Task & 0.003 & -0.13 & 0.005 & -0.04 & 1.58 & 5.67 & 0.01 & $17,956 * * *$ \\
\hline Serial Pos. * Task & 0.01 & -0.14 & 0.01 & -0.04 & 1.60 & -0.28 & $0.01 \&-0.003$ & 17,998 \\
\hline Temp. C. * Task & 0.08 & -0.14 & 0.05 & -0.05 & 1.60 & 11.01 & 0.01 & $17,996^{* *}$ \\
\hline Sem. C. * Task & 0.01 & -0.13 & 0.005 & -0.04 & 1.50 & 1.71 & 0.19 & 17,999 \\
\hline
\end{tabular}

** Model with the interaction term has a significantly better fit than the model without the interaction term, $\chi 2(1)=7.32, p=.007, * * *$ Model with the interaction term has a significantly better fit than the model without the interaction term, $\chi 2(1)=87.20, p<.001$

Table S2B. Experiment 2 Markov Chain process model coefficients.

In summary, our model is a Markov chain model, with transition probabilities depending on state-invariant variables, such as the serial positions and preferences for the items, as well as state-dependent variables, such as temporal proximity (in the presented list) and semantic 
similarity to the previously recalled item. We allow the effects of these variable to depend on the task, using interaction effects. The rows of the transition probabilities matrix $M$ indicate the identity of the previously recalled item, and the columns indicate the probability of the next recall being any one of the 25 studied items (which is based on the state-dependent and state-independent variables, and potentially their interaction with task). Thus, from recall event to recall event, the model jumps from row to row, with the probability of each jump specified in the corresponding column. In fitting the model, we use the predicted probability of sampling the observed item (i.e. the probability obtained from the corresponding column), in order to calculate the log-likelihood of a particular set of parameters. It is important to note that the temporal clustering term has a negative coefficient as the smaller values of lags give larger probabilities of recall. This may not appear intuitive in the first place. In addition, intrusions were rare in our study. As intrusions were impossible to model using our computational framework, and were unlikely to alter our main results, we removed all intrusions from the data prior to our analyses.

\section{Model Simulations}

In order to validate and demonstrate the utility of our computational approach, we simulated recall data using our model's best fit coefficients. To minimize random noise, we simulated 100 recall sequences for each participant. Next, we used these simulations to produce the same behavioral data patterns that we previously examined with real data. We include the behavioral graphs from model simulations in Figures S1-2. As in can be seen, our model was able to successfully generate the behavioral patterns that emerged in human data. There are a few observations to note about the simulated data patterns. First, even though the general pattern of temporal clustering is present in our simulations, since we have a simple linear model, we were not able to capture the nonlinear dropout after the +1 and -1 lags. In addition, we were also unable to demonstrate the forward asymmetry in the lag-CRP curve. However, there is no doubt 
that more complicated versions of our model will be able to adjust for those nuances in the data. Second, the serial position curve in Figure S1D appears to have a greater difference between recall probabilities between standard recall and choice-directed recall tasks. Since the human data demonstrates a slightly higher number of unique words remembered by participants in the choice-directed recall task, this pattern is not surprising in simulated data. However, overall, our simulations capture a great amount of variability observed in the real data.
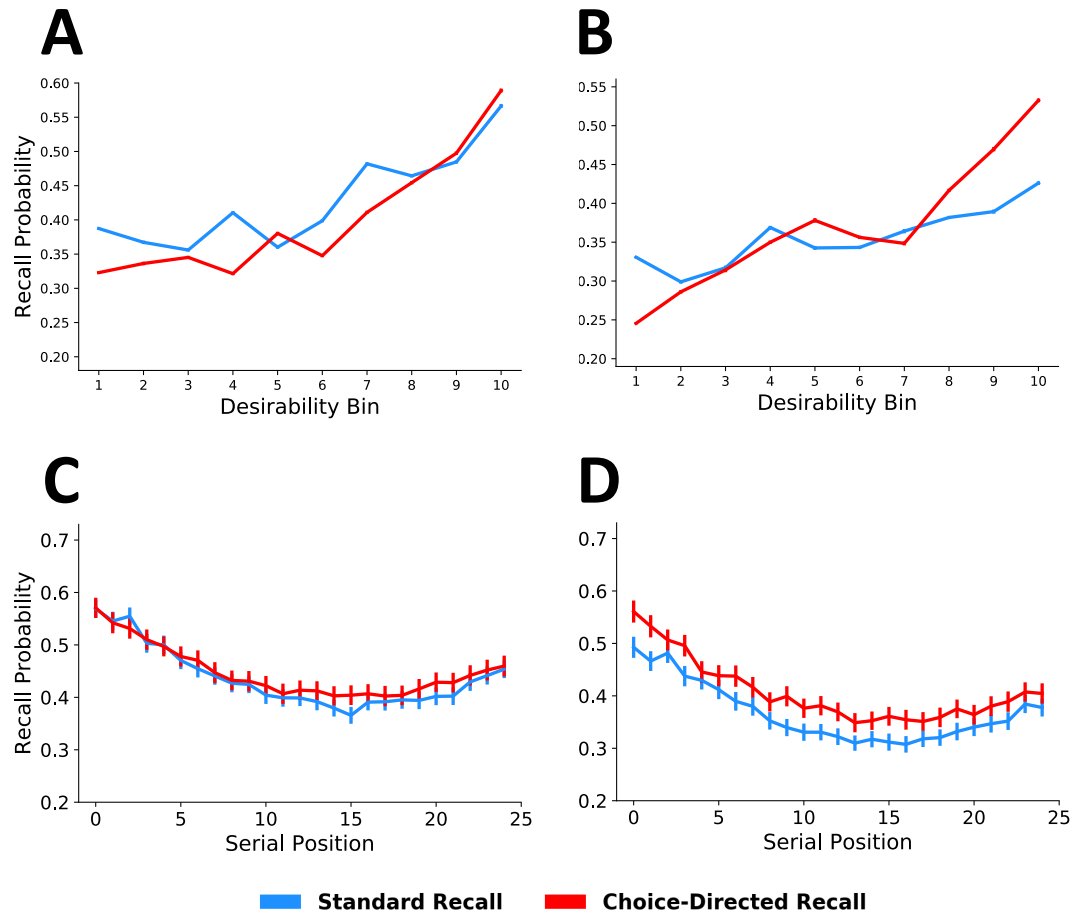

Figure S1. Simulated Model Data. Predicted influence of desirability on recall in Experiment 1 (Figure 2A) and in Experiment 2 (Figure 2B). We partitioned all possible desirability ratings into ten equally spaced bins (with bin 1 consisting of the set of items that received the lowest desirability ratings), and then plotted the aggregate predicted probability of recall for items in each bin. Influence of encoding serial position on predicted recall in Experiment 1 (Figure 2C) and in Experiment 2 (Figure 2D). Error bars are $\mp 1 S E M$. 

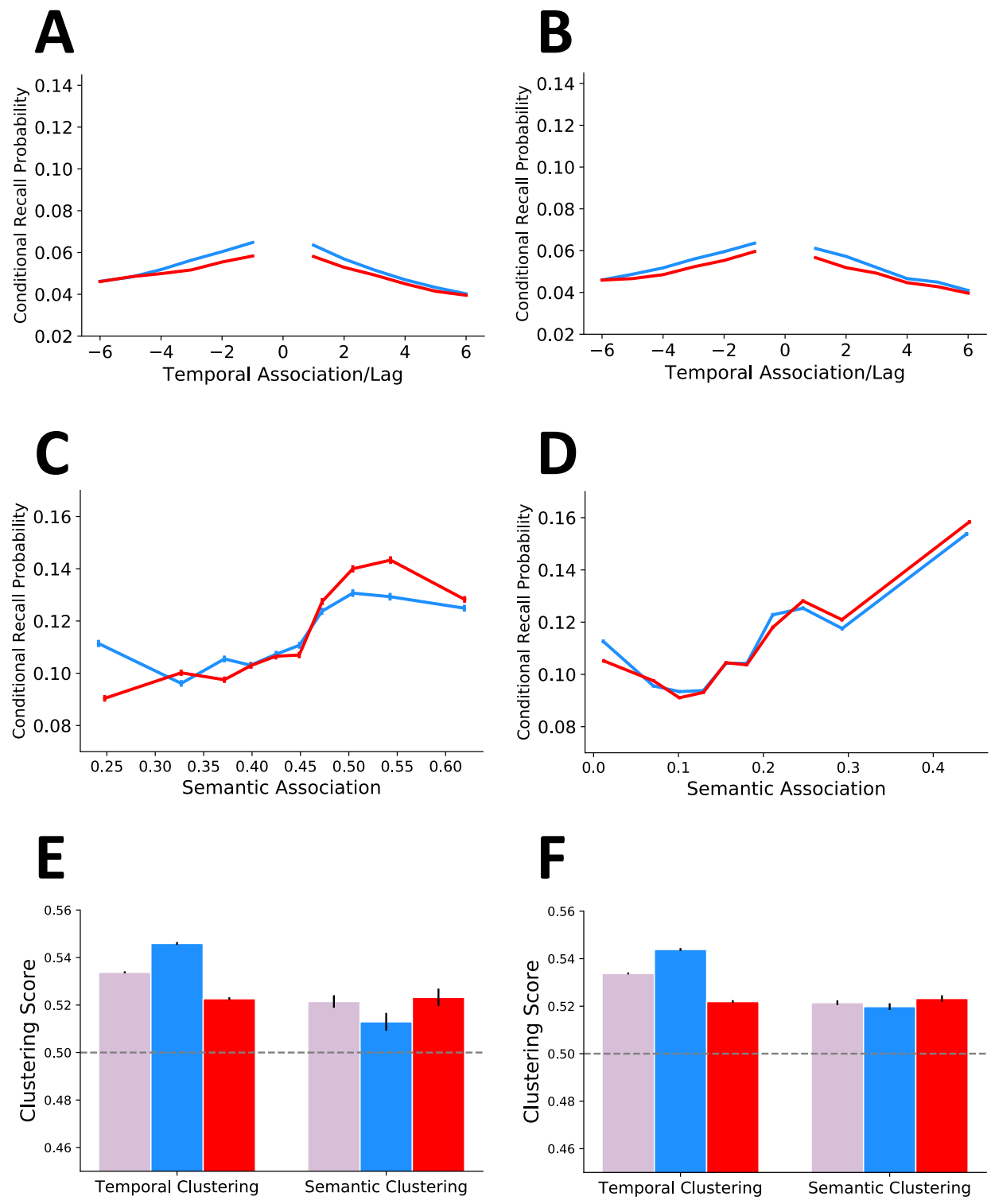

All Conditions

Standard Recall

Choice-Directed Recall

Figure S2. Simulated Model Data. Predicted temporal and semantic clustering in both experiments. Predicted conditional recall probability (CRP) of items as a function of temporal association/lag in Experiment 1 (Figure 3A) and in Experiment 2 (Figure 3B). Here, a lag of $\mathrm{k}$ shows the predicted probability of recalling an item presented $\mathrm{k}$ positions after (for positive $\mathrm{k}$ ) or before (for negative $\mathrm{k}$ ) a just-recalled item, and a higher CRP for small absolute lags indicates the emergence of temporal clustering. Predicted conditional recall probability (CRP) of items as a function of semantic association in Experiment 1 (Figure 3C) and in Experiment 2 (Figure 
3D). Here, a higher CRP for higher levels of semantic associations (i.e. positively sloped line) indicates that there is a larger predicted probability of recalling an item that is highly similar to a just presented item, which is evidence for semantic clustering. Average temporal and semantic clustering scores in Experiment 1 (Figure 3E) and in Experiment 2 (Figure 3F). Error bars are 干1 SEM.

We also computed $\mathrm{R}^{2}$ statistics regarding the predictive power of our model for the key feature of the data. These statistics show that our model is able to accurately predict observed patterns of desirability (mean $\mathrm{R}^{2}=0.74$ ), serial position (mean $\mathrm{R}^{2}=0.64$ ), semantic clustering (mean $\mathrm{R}^{2}=0.62$ ), and temporal clustering (mean $\left.\mathrm{R}^{2}=0.48\right)$.

\section{Experiment 1}

\section{Experiment 2}

\section{Standard Recall Choice-Directed Recall Standard Recall Choice-Directed Recall}

\begin{tabular}{lllll}
\hline Serial Position & $0.70(r=0.84)$ & $0.64(r=0.81)$ & $0.74(r=0.86)$ & $0.46(r=0.68)$ \\
Desirability & $0.75(r=0.87)$ & $0.80(r=0.89)$ & $0.54(r=0.74)$ & $0.87(r=0.93)$ \\
Temporal C. & $0.41(r=0.64)$ & $0.45(r=0.67)$ & $0.31(r=0.56)$ & $0.74(r=0.86)$ \\
Semantic C. & $0.44(r=0.66)$ & $0.67(r=0.82)$ & $0.59(r=0.77)$ & $0.76(r=0.87)$ \\
\hline
\end{tabular}

Table S3. $\mathrm{R}^{2}$ statistics regarding the predictive power of our model for the key feature of the data. Pearson's $r$ correlation coefficients are included in the parentheses.

While the influence of temporal clustering can only appear when people are transitioning from one item to another, desirability may be influential both for the first recall and in the transitions between subsequent recalls. If desirability is differentially influential in choicedirected vs. standard recall only for the first recall, its unique effect in choice-directed recall can be seen as involving only the starting point of memory search. However, if it is differentially influential during transition, its effect can be seen in terms of a persistent bias that influences every step of memory search. To disentangle these two potential effects of desirability, our final analyses had separate weights corresponding to the mechanisms that are in play for starting 
activations and transition activations. Thus, the previous model was transformed into the following form:

$A_{i j}(0)=\beta_{\text {Dstarting }} *$ Desirability $j+\beta_{P \text { Starting }} *$ Serial Position $j+\beta_{R \text { Starting }} *$ Serial Position ${ }^{2} j+\beta_{C} *$ Task

$A_{i j}(t)=\beta_{D \text { Transition }} *$ Desirability $j+\beta_{P \text { Transition }} *$ Serial Position $j+\beta_{R \text { Transition }} *$ Serial Position ${ }^{2} j+\beta_{\text {Temp Transition }} *$ Temporal Association $i j+\beta_{\text {Sem Transition }}$ * Semantic Associations $i j+\beta_{C} *$ Task

As part of our fits, we also had three additional models. In these models, a task interaction term was included with desirability starting, desirability transition, or both (the full model). Then, we conducted a likelihood ratio tests between the full model and the rest of the models, to evaluate whether or not removing the remaining interactions result in worse fits.

Once again, we fit our model using maximum likelihood estimation (with Nelder-Mead method). However, we also used previous model coefficients to inform us about reasonable starting point values for each of the variables. After inserting these starting point values, each model was fit 30 times to ensure that the parameters stabilize.

The results of this regression are shown in Table $S 4 A-C$, which also compare the full model with each of the three remaining models. Here we see that allowing for a desirability interaction with task on both the starting point and on transition probabilities results in the best fits. Thus, desirability does not only differentially influence memory at the beginning of retrieval, but also persists as a consistent effect while participants continue to remember more items during choice-directed recall. 


\begin{tabular}{ccccccc}
\hline & \multicolumn{3}{c}{ Experiment 1 } & \multicolumn{2}{c}{ Experiment 2 } \\
Model & $\begin{array}{c}\text {-Log } \\
\text { Likelihood }\end{array}$ & $\begin{array}{c}\text { Chi- } \\
\text { Square }\end{array}$ & P-Value & $\begin{array}{c}\text {-Log } \\
\text { Likelihood }\end{array}$ & $\begin{array}{c}\text { Chi- } \\
\text { Square }\end{array}$ & $\begin{array}{c}\text { P- } \\
\text { Value }\end{array}$ \\
\hline Base Model & 19,920 & 144.5 & $<.001$ & 18,010 & 230.90 & $<.001$ \\
w/ Desirability Starting * Task & 19,857 & 17.98 & $<.001$ & 17,930 & 70.44 & $<.001$ \\
w/ Desirability Transition * Task & 19,873 & 49.80 & $<.001$ & 17,930 & 70.46 & $<.001$ \\
$\begin{array}{c}\text { w/ Desirability Starting * Task + } \\
\text { Desirability Transition * Task }\end{array}$ & 19,848 & & & 17,895 & & \\
\hline
\end{tabular}

Table S4A. Comparisons between models with task-based interactions with the

desirability on starting point, transition probability, or neither, and the full model (with task-

based interactions with the desirability on both starting point and transition probability). The chi-

square values involve log-likelihood differences between the full model and each of the

remaining models, and indicate whether or not removing the remaining interactions result in

worse fits.

\begin{tabular}{|c|c|c|c|c|c|c|c|c|c|c|c|c|}
\hline & $\begin{array}{l}\text { Desirability } \\
\text { Starting }\end{array}$ & $\begin{array}{c}\text { Serial } \\
\text { Position } \\
\text { Starting }\end{array}$ & $\begin{array}{l}\text { Serial } \\
\text { Position } \\
\text { Squared } \\
\text { Starting } \\
\end{array}$ & $\begin{array}{c}\text { Desirability } \\
\text { Transition }\end{array}$ & $\begin{array}{c}\text { Serial Position } \\
\text { Transition }\end{array}$ & $\begin{array}{c}\text { Serial Position } \\
\text { Squared } \\
\text { Transition }\end{array}$ & $\begin{array}{l}\text { Temp C. } \\
\text { Transition }\end{array}$ & $\begin{array}{l}\text { Sem C. } \\
\text { Transition }\end{array}$ & $\begin{array}{l}\text { Task } \\
\end{array}$ & $\begin{array}{c}\text { Task } \\
\text { Interaction } \\
\text { w/ Pref } \\
\text { Starting } \\
\end{array}$ & $\begin{array}{c}\text { Task } \\
\text { Interaction } \\
\text { w/ Pref } \\
\text { Transition } \\
\end{array}$ & $-\mathbf{L L}$ \\
\hline Base Model & 0.04 & -0.19 & 0.01 & 0.01 & -0.09 & 0.003 & -0.03 & 1.34 & 3.95 & & & $19,920 * * *$ \\
\hline Des. Starting * Task & 0.01 & -0.42 & 0.02 & 0.01 & -0.10 & 0.004 & -0.04 & 1.63 & -2.29 & 0.03 & & $19,857 * * *$ \\
\hline Des. Transition * Task & 0.02 & 1.83 & 0.45 & 0.01 & 0.49 & 0.21 & -0.03 & 1.58 & -0.70 & & 0.002 & $19,873 * * *$ \\
\hline $\begin{array}{c}\text { Des. Starting * Task+ } \\
\text { Des. Transition * Task }\end{array}$ & 0.01 & -0.38 & 0.01 & 0.01 & -0.10 & 0.004 & -0.04 & 1.92 & 2.65 & 0.02 & 0.002 & 19,848 \\
\hline
\end{tabular}

*** Model with the interaction term has a significantly better fit than the model without the interaction term, $\chi 2(1) \geq 17.98, p<.001$

Table S4B. Experiment 1 Markov Chain process model coefficients.

\begin{tabular}{|c|c|c|c|c|c|c|c|c|c|c|c|c|}
\hline & $\begin{array}{l}\text { Desirability } \\
\text { Starting }\end{array}$ & $\begin{array}{l}\text { Serial } \\
\text { Position } \\
\text { Starting }\end{array}$ & $\begin{array}{c}\text { Serial } \\
\text { Position } \\
\text { Squared } \\
\text { Starting } \\
\end{array}$ & $\begin{array}{c}\text { Desirability } \\
\text { Transition }\end{array}$ & $\begin{array}{c}\text { Serial } \\
\text { Position } \\
\text { Transition }\end{array}$ & $\begin{array}{c}\text { Serial } \\
\text { Position } \\
\text { Squared } \\
\text { Transition } \\
\end{array}$ & $\begin{array}{c}\text { Temp C. } \\
\text { Transition }\end{array}$ & $\begin{array}{c}\text { Sem C. } \\
\text { Transition }\end{array}$ & Task & $\begin{array}{c}\text { Task } \\
\text { Interaction } \\
\text { w/Pref } \\
\text { Starting } \\
\end{array}$ & $\begin{array}{c}\text { Task } \\
\text { Interaction } \\
\text { w/ Pref } \\
\text { Transition } \\
\end{array}$ & $-\mathbf{L L}$ \\
\hline Base Model & 0.02 & -041 & 0.02 & 0.01 & -0.02 & -2.83 & -0.04 & 1.62 & 49.91 & & & $18,010^{* * *}$ \\
\hline Des. Starting * Task & 0.01 & -0.49 & 0.02 & 0.01 & -0.09 & 0.00 & -0.04 & 1.29 & 0.56 & 0.01 & & $17,930 * * *$ \\
\hline Des. Transition * Task & 0.02 & -0.38 & 0.01 & 0.00 & -0.10 & 0.00 & -0.05 & 2.02 & -8.77 & & 0.01 & $17,930 * * *$ \\
\hline $\begin{array}{l}\text { Des. Starting * Task }+ \\
\text { Des. Transition * Task }\end{array}$ & 0.01 & -0.30 & 0.01 & 0.01 & -0.11 & 0.00 & -0.04 & 0.95 & 1.61 & 0.02 & 0.01 & 17,895 \\
\hline
\end{tabular}

*** Model with the interaction term has a significantly better fit than the model without the interaction term, $\chi 2(1) \geq 72.44, p<.001$

Table S4C. Experiment 2 Markov Chain process model coefficients. 


\section{Analyses With Frequency of Consumption Ratings}

In our experimental design, we not only collected desirability ratings for each item, but also gathered frequency of consumption ratings. However, we found these two variables to be very highly correlated $(r=.65, p<.001$ in Experiment 1 and $r=.44, p<.001$ in Experiment 2$)$, which could lead to potential multicollinearity issues in the analysis. Thus, while the main text includes all of the results using only the desirability variable, we performed the same analyses using the frequency of consumption variable below. Mixed effects regression model results (are followed by the computational memory model results.

As seen in Table S5, frequency not only had a significantly positive overall effect on recall, but also a significant interaction in both Experiment 1 and Experiment 2. These significant interactions suggest that frequently consumed (infrequently consumed) items are more (less) likely to be remembered in choice-directed recall relative to standard recall. If we look at results from our computational memory model, shown in Tables $S 6 A-B$, the frequency of consumption variable was significantly more influential for the choice-directed recall task in both Experiment 1 and 2. Furthermore, the temporal clustering variable was significantly less influential for the choice-directed recall task in the two experiments.

In sum, these additional analyses confirm that our general findings were replicated when using the frequency of consumption variable instead of the desirability variable. Thus, it is possible to generalize our results and conclude that memory-based decision making prioritizes decision-relevant information such as desirability and frequency of consumption. 


\begin{tabular}{lrcrr} 
Model for Frequency & \multicolumn{2}{c}{ Experiment 1 } & \multicolumn{2}{c}{ Experiment 2 } \\
\hline Estimate & $\boldsymbol{\beta}$ & $\mathbf{9 5 \%} \boldsymbol{C I}$ & $\boldsymbol{\beta}$ & \multicolumn{1}{c}{$\mathbf{9 5 \%} \boldsymbol{C I}$} \\
\hline Intercept & $-0.31^{* * *}$ & {$[-0.42,-0.21]$} & $-0.55^{* * *}$ & {$[-0.68,-0.41]$} \\
Frequency & $0.005^{* * *}$ & {$[0.004,0.008]$} & $0.007^{* * *}$ & {$[0.004,0.008]$} \\
Task & $-0.16^{*}$ & {$[-0.31,-0.003]$} & 0.05 & {$[-0.16,0.24]$} \\
Frequency * Task & $0.005^{* *}$ & {$[0.002,0.008]$} & $0.005^{* *}$ & {$[0.002,0.009]$} \\
\hline
\end{tabular}

Table S5. Experiments 1 and 2 separate mixed effects model coefficients with frequency.

\begin{tabular}{lcccccccl}
\hline & Freq. & $\begin{array}{c}\text { Serial } \\
\text { Position }\end{array}$ & $\begin{array}{c}\text { Serial } \\
\text { Position } \\
\text { Squared }\end{array}$ & $\begin{array}{c}\text { Temp } \\
\text { C. }\end{array}$ & $\begin{array}{c}\text { Sem } \\
\text { C. }\end{array}$ & Task & $\begin{array}{c}\text { Task } \\
\text { Interaction }\end{array}$ & - LL \\
\hline Base Model & 0.01 & -0.11 & 0.004 & -0.04 & 1.60 & 8.02 & & 19,937 \\
Freq. * Task & 0.01 & -0.11 & 0.004 & -0.04 & 1.60 & -37.16 & 0.004 & $19,927 * * *$ \\
Primacy * Task & 0.01 & -0.13 & 0.004 & -0.03 & 1.84 & -0.62 & $0.02 \&-0.00$ & 19,937 \\
Temp C. * Task & 0.01 & -0.11 & 0.00 & -0.04 & 1.59 & -15.46 & 0.02 & $19,930 * * *$ \\
Sem C. * Task & 0.01 & -0.11 & 0.004 & -0.04 & 1.57 & 6.81 & 0.06 & 19,936 \\
\hline
\end{tabular}

*** Model with the interaction term has a significantly better fit than the model without the interaction term, $\chi 2(1) \geq 12.50, p<.001$

Table S6A. Experiment 1 Markov Chain process model coefficients with frequency

\begin{tabular}{lcccccccl}
\hline & Freq. & $\begin{array}{c}\text { Serial } \\
\text { Position }\end{array}$ & $\begin{array}{c}\text { Serial } \\
\text { Position } \\
\text { Squared }\end{array}$ & $\begin{array}{c}\text { Temp } \\
\text { C. }\end{array}$ & $\begin{array}{c}\text { Sem } \\
\text { C. }\end{array}$ & Task & $\begin{array}{c}\text { Task } \\
\text { Interaction }\end{array}$ & - LL \\
\hline Base Model & 0.01 & -0.14 & 0.005 & -0.04 & 1.65 & -2.31 & & 18,008 \\
Freq. * Task & 0.004 & -0.13 & 0.005 & -0.04 & 1.64 & 0.81 & 0.006 & $17,987^{* * *}$ \\
Primacy * Task & 0.01 & -0.14 & 0.005 & -0.04 & 1.65 & 1.04 & $0.02 \&-0.00$ & $18,005^{*}$ \\
Temp C. * Task & 0.01 & -0.13 & 0.00 & -0.04 & 1.65 & -4.09 & 0.01 & $18,004^{* *}$ \\
Sem C. * Task & 0.01 & -0.14 & 0.005 & -0.04 & 1.56 & 5.17 & 0.17 & 18,008 \\
\hline
\end{tabular}

* Model with the interaction term has a significantly better fit than the model without the interaction term, $\chi 2(1)=5.52, p=.02, * * *$ Model with the interaction term has a significantly better fit than the model without the interaction term, $\chi 2(1)$ $=7.26, p<.01, * * *$ Model with the interaction term has a significantly better fit than the model without the interaction term, $\chi 2(1)=42.0, p<.001$

Table S6B. Experiment 2 Markov Chain process model coefficients with frequency. 
Experimental Stimuli

\begin{tabular}{|c|c|c|}
\hline \multirow[b]{2}{*}{ Word } & \multicolumn{2}{|c|}{$\begin{array}{c}\text { Experiment } 1 \\
\text { Average Recall Probability }\end{array}$} \\
\hline & Standard Recall & Choice-Based Recall \\
\hline burrito & 0.43 & 0.43 \\
\hline casserole & 0.38 & 0.34 \\
\hline cheeseburger & 0.66 & 0.51 \\
\hline cheesecake & 0.38 & 0.41 \\
\hline chili & 0.34 & 0.36 \\
\hline chips & 0.33 & 0.26 \\
\hline chowder & 0.27 & 0.27 \\
\hline cookie & 0.39 & 0.38 \\
\hline cornbread & 0.28 & 0.3 \\
\hline crepe & 0.4 & 0.35 \\
\hline croissant & 0.34 & 0.35 \\
\hline cupcake & 0.41 & 0.36 \\
\hline custard & 0.28 & 0.18 \\
\hline doughnut & 0.37 & 0.4 \\
\hline enchilada & 0.52 & 0.44 \\
\hline granola & 0.2 & 0.32 \\
\hline grits & 0.44 & 0.34 \\
\hline gumbo & 0.45 & 0.35 \\
\hline hamburger & 0.73 & 0.65 \\
\hline hummus & 0.39 & 0.42 \\
\hline jambalaya & 0.57 & 0.45 \\
\hline jelly & 0.3 & 0.26 \\
\hline kebab & 0.33 & 0.29 \\
\hline macaroni & 0.45 & 0.45 \\
\hline macaroon & 0.4 & 0.37 \\
\hline meatball & 0.42 & 0.5 \\
\hline meatloaf & 0.29 & 0.32 \\
\hline muffin & 0.34 & 0.36 \\
\hline nacho & 0.41 & 0.47 \\
\hline noodles & 0.37 & 0.43 \\
\hline oatmeal & 0.38 & 0.41 \\
\hline omelet & 0.4 & 0.27 \\
\hline pancake & 0.44 & 0.38 \\
\hline pasta & 0.62 & 0.5 \\
\hline pizza & 0.75 & 0.61 \\
\hline
\end{tabular}




$\begin{array}{ccc}\text { popcorn } & 0.31 & 0.22 \\ \text { pretzel } & 0.32 & 0.28 \\ \text { pudding } & 0.32 & 0.28 \\ \text { quiche } & 0.52 & 0.31 \\ \text { ravioli } & 0.52 & 0.5 \\ \text { rice } & 0.57 & 0.47 \\ \text { risotto } & 0.34 & 0.31 \\ \text { salad } & 0.43 & 0.49 \\ \text { sandwich } & 0.4 & 0.39 \\ \text { sausage } & 0.42 & 0.35 \\ \text { soup } & 0.37 & 0.38 \\ \text { spaghetti } & 0.58 & 0.65 \\ \text { steak } & 0.45 & 0.53 \\ \text { sushi } & 0.49 & 0.43 \\ \text { tiramisu } & 0.58 & 0.43\end{array}$




\begin{tabular}{|c|c|c|}
\hline \multirow[b]{2}{*}{ Word } & \multicolumn{2}{|c|}{$\begin{array}{c}\text { Experiment } 2 \\
\text { Average Recall Probability }\end{array}$} \\
\hline & Standard Recall & Choice-Based Recall \\
\hline bracelet & 0.8378 & 0.8125 \\
\hline calendar & 0.4541 & 0.4432 \\
\hline candle & 0.3243 & 0.3693 \\
\hline cap & 0.2486 & 0.2955 \\
\hline flower & 0.3676 & 0.2784 \\
\hline frame & 0.5081 & 0.4375 \\
\hline gloves & 0.3243 & 0.3182 \\
\hline liquor & 0.3081 & 0.3466 \\
\hline magnet & 0.3514 & 0.3352 \\
\hline mug & 0.2649 & 0.2386 \\
\hline necklace & 0.4108 & 0.4148 \\
\hline notebook & 0.4595 & 0.4375 \\
\hline pen & 0.3243 & 0.3352 \\
\hline pillow & 0.5676 & 0.6023 \\
\hline pin & 0.3459 & 0.3068 \\
\hline plant & 0.4541 & 0.4318 \\
\hline poster & 0.3243 & 0.3693 \\
\hline puzzle & 0.2162 & 0.2102 \\
\hline scarf & 0.227 & 0.267 \\
\hline socks & 0.4649 & 0.4886 \\
\hline statue & 0.3514 & 0.4205 \\
\hline towel & 0.2432 & 0.2386 \\
\hline tray & 0.2811 & 0.3068 \\
\hline vase & 0.3135 & 0.25 \\
\hline wallet & 0.4865 & 0.4659 \\
\hline
\end{tabular}

